\title{
Electrical Double Layer in Imidazolium Chloroaluminate Ionic Liquids and Its Influence on the Surface Morphology of Aluminium Deposits
}

\author{
Yong Zheng ${ }^{1, *}$, Yongjun Zheng ${ }^{1}$, Conghu Peng ${ }^{1}$, Zhijun Zhao ${ }^{2}$, Dayong Tian ${ }^{1}$ \\ ${ }^{1}$ College of Chemistry and Environmental Engineering, Anyang Institute of Technology, Anyang \\ 455000, Henan, P. R. China \\ ${ }^{2}$ State Key Laboratory of Chemical Engineering, Department of Chemical Engineering, Tsinghua \\ University, Beijing 100084, P. R. China \\ "E-mail: yzheng83@126.com
}

doi: $10.20964 / 2016.11 .88$

Received: 21 June2016/ Accepted: 27 August 2016 / Published: 10 October 2016

\begin{abstract}
The traditional electrolytic process in aluminium industry suffers from many inherent problems, which are mainly owing to the natural drawbacks of electrolytes. The development of ionic liquid provides a promising approach for low-temperature aluminium electrodeposition. Although extensive research has been reported, the relationship between ionic liquids' structure and electrodeposition process is still little understood. To investigate this fundamental issue, some typical imidazolium chloroaluminate ionic liquids were synthesized and investigated as electrolytes in this work. Experimental results show that the structure of cation has significant effect on surface morphology of aluminium deposits. This fact results from the different structure of electrical double layer at electrode interface. Based on theoretical calculations, it's first found that aluminium is harder to be electrodeposited and the average grain size of deposits becomes larger with increasing cation-anion interaction energy. In such case, $\left[\mathrm{Al}_{2} \mathrm{Cl}_{7}\right]^{-}$anion cannot easily penetrate double layer and be adsorbed onto the electrode, which always results in larger aluminium crystals. Furthermore, the value of interaction energy is proved to be highly affected by the structure of $N$-alkyl side chain, especially functional group. Therefore, interaction energy should be adjusted to a lower value by regulating the structure of imidazolium cation, in order to achieve finer and smoother aluminium crystals from chloroaluminate ionic liquids. It's expected that present work will help to promote the future research in this important field.
\end{abstract}

Keywords: electrical double layer; aluminium; morphology; chloroaluminate ionic liquids

\section{$\underline{\text { FULL TEXT }}$}

(C) 2016 The Authors. Published by ESG (www.electrochemsci.org). This article is an open access article distributed under the terms and conditions of the Creative Commons Attribution license (http://creativecommons.org/licenses/by/4.0/). 